\title{
"Habemus Papam" e a história das Missões jesuíticas na bacia do Prata
}

Barbara Freitag

OM A ELEIÇÃo de Jorge Mario Bergoglio como sucessor de Bento XVI em março de 2013, os fiéis católicos foram surpreendidos com o fato de que pela primeira vez na milenar história do papado um jesuita ocupa o "trono de Pedro" em Roma. Ser argentino e escolher o nome Francisco foram qualificações adicionais que reforçaram essa surpresa. Até mesmo a mídia tecnologicamente potente e onipresente pouco ou nada sabia sobre a origem e história do cardeal de Buenos Aires, que dedicava sua vida aos pobres e com eles partilhava a "sorte" de viver quase fora, no sul, "no fim do mundo", nas palavras do recém-eleito papa Francisco.

Para reduzir essa "ignorância” e fundamentar historicamente a origem, o auge e a destruição das "missões jesuíticas" na bacia do Prata, somente posso recomendar a leitura e apropriação cuidadosa de um livro que em mais de 300 páginas reconstrói a história das missões jesuíticas (1609-1767) instaladas às margens dos rios Paraguai, Paraná, Uruguai e seu afluentes.

Seu autor, Miranda Neto, é economista (UFRJ) de formação, tem pós-graduação em Economia Rural em Stanford, é especialista em Planejamento Urbano e Regional (Ibam), e fez aperfeiçoamento em Desenvolvimento Agrícola (Fundação Getúlio Vargas), entre outras. Trabalhou como professor visitante na Universidade Livre de Berlim e como jornalista da Gazeta Mercantil (Rio) e do jornal $O$ Liberal (Belém). O livro foi prefaciado pelo diplomata e historiador Vasco Mariz, e tem belo texto de quarta capa da escritora e historiadora Mary del Priore. A ficha catalográfica, elaborada por Valéria Alves Werneck, o classifica em duas categorias: 1.Jesuítas Brasil. 2. Missões religiosas.

O autor nos traz uma amostra de fotos (das ruínas) e da arte missioneira, que dominou, durante mais de 150 anos (1609-1767), a bacia do Prata, envolvendo a Bolívia, o Paraguai, a Argentina, o Uruguai e o Brasil. Miranda Neto cobre assim um longo período de formação das colônias espanhola e portuguesa no sul da América do Sul, envolvendo a colônia de Sacramento, a Província Cisplatina, vários Tratados entre Portugal e Espanha (Tordesilhas, de Madri), abrangendo ainda a luta de povos indígenas entre si, dos guaranis com os colonos e das missões com os bandeirantes e paulistas. $\mathrm{O}$ autor ainda chama atenção para os interesses disfarçados dos viajantes europeus do século XIX, convencidos de que onde há índios, há minas de ouro e prata, que estariam sendo exploradas clandestinamente (p.140).

Miranda Neto realizou ao mesmo tempo um trabalho multidisciplinar, intercultural e enciclopédico, para fornecer-nos um relato científico, devidamente fundamentado, do entrosamento entre colonizadores ibéricos e povos indígenas, das mais diferentes nações, linguagens e culturas. Enquanto economista, interessou-se mais pela organização da produção, sustentabilidade eco- 
nômica e ecológica, do que pelos rituais religiosos e culturais, típicos da antropologia moderna, que condena tematizar e praticar a aculturação e assimilação dos povos indígenas aos interesses do colonizador europeu e defende a necessidade de "preservar" a cultura autóctone dos habitantes originais do Novo Mundo.

A peculiaridade do olhar do autor é revelada em $A$ utopia possípel, seu amplo e fascinante estudo de uma época, que tão poucos vestígios deixou e cujo mérito é, por isso mesmo, inquestionável. Ao caracterizar o período de 1609 a 1767 como "utopia possível", Miranda acena com o fato de que os jesuítas tentaram concretizar um projeto, cujos objetivos não foram alcançados plenamente; no entanto, focaliza e sublinha os extraordinários e inesperados resultados obtidos durante século e meio de paciente trabalho, realizado pelos enviados da ordem de Inácio de Loyola, que conseguiram transformar os povos indígenas, primitivos habitantes da bacia do Prata, de nômades (tupi-guaranis) em sedentários, povos bélicos em agricultores pacíficos, povos ainda canibais e polígamos em criadores de gado e comunidades pacíficas baseadas na unidade familiar por meio de suas técnicas pacientes de educação e evangelização (p.98-9).

Talvez a excepcionalidade desses fatos somente fique evidente quando compararmos o choque de culturas havido entre os colonos ibéricos e europeus com as nações indígenas que habitavam o novo Mundo. Enquanto Cortez, Pizarro ou Aguirre e seus homens, ávidos pela caça do ouro e de riquezas acumuladas por esses povos autóctones, acabaram destruindo as culturas encontradas (aztecas, toltecas, maias, incas), também no Brasil os guarás, apiacás, munduru-

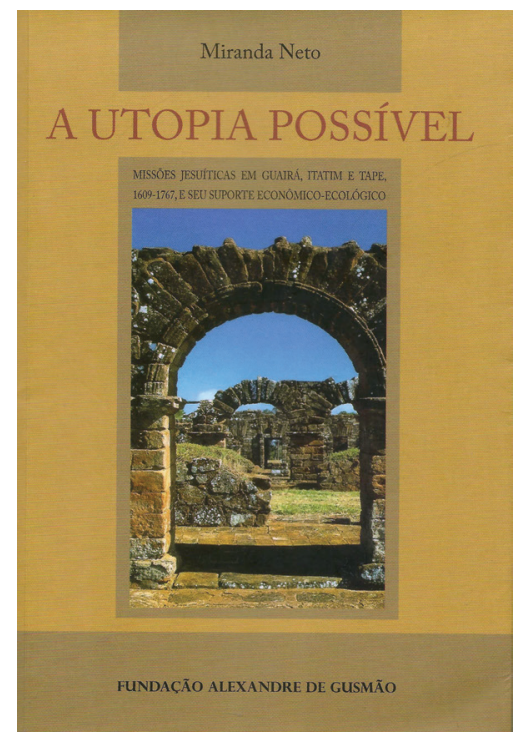

MIRANDA NETO, M. J. de. A utopia possípel - Missões jesuiticas em Guairá, Itatim e Tape, 1609-1767, e seu suporte econômico-ecológico. Brasília: Fundação

Alexandre de Gusmão, 2012. 237p.

cus, bororos, botocudos, para mencionar somente alguns, foram dizimados, escravizados, exterminados, liquidados, pelos aventureiros e colonos portugueses (e espanhóis). Enquanto isso, os jesuítas dos Povos das Missões erigiram comunidades pacíficas, sedentárias, baseadas em uma economia agrária e de criação de gado, sustentável e ecológica, até para os padrões de hoje.

Alexandre Rodrigues Ferreira (17561815), o primeiro cientista natural a desbravar a Amazônia e o Pantanal, foi um dos primeiros a denunciar o equívoco da política brutal de obtenção de mão de obra barata com a perseguição dos indígenas nômades e a organização dos “descimentos", uma verdadeira caça e extermínio dos povos indígenas da bacia do Amazonas à bacia do Prata. Seguiram-se depois as entradas e bandei- 


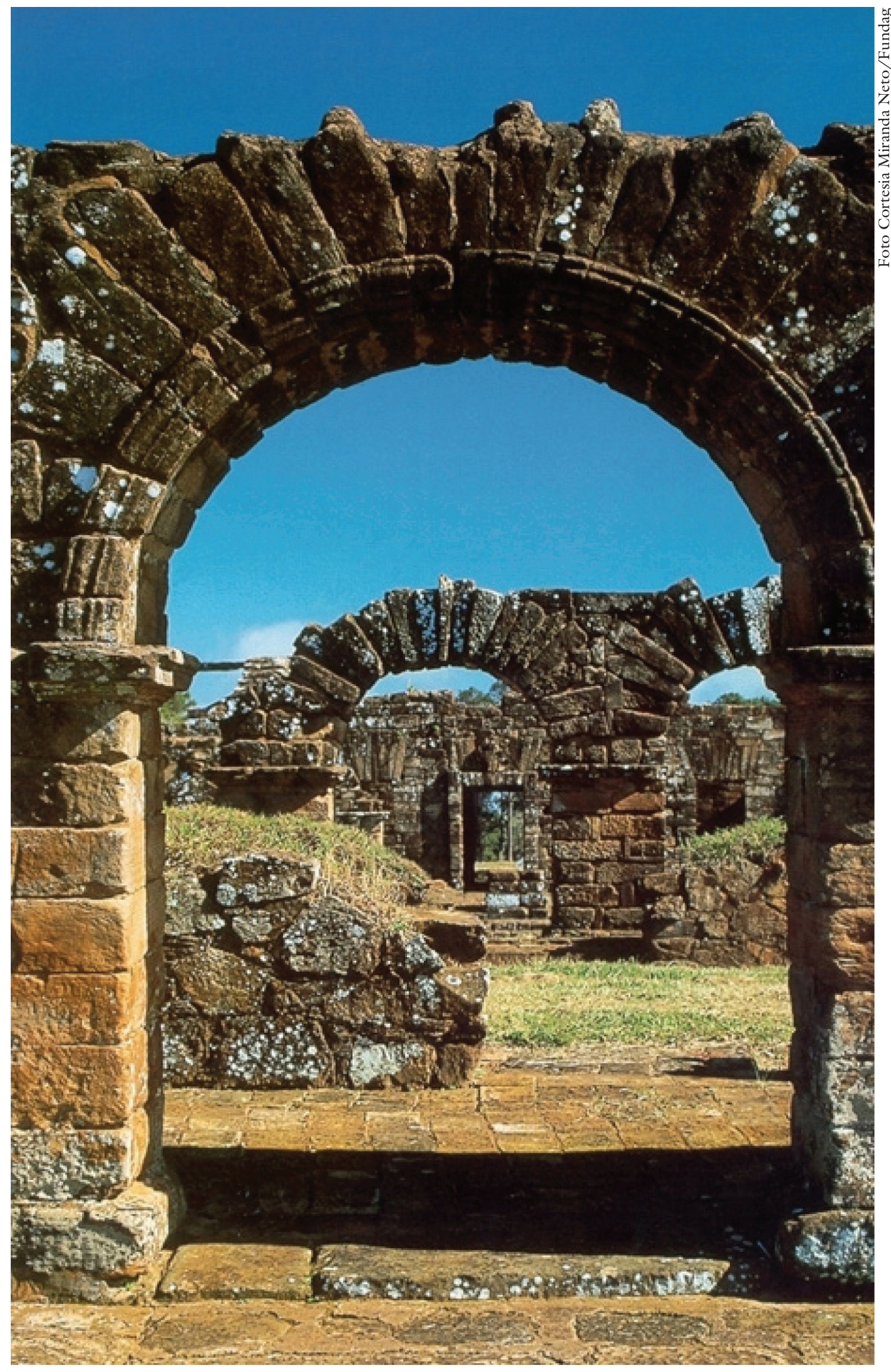


ras vindas do planalto paulista, que durante todo o século XVIII conseguiram dizimar e finalmente destruir as Missões jesuíticas.

Até a expulsão dos jesuítas da América com a dissolução da ordem em Roma, os padres da Ordem de Santo Inácio de Loyola aproximaram-se dos povos tupi-guaranis, esforçavam-se em aprender a sua língua, seus rituais, seduzi-los com música, de forma pacífica, para assentá-los em aldeias e "missões", oferecendo-lhes formas dignas e sustentáveis de sobrevivência.

Isso, e muito mais, nos é desvendado por Miranda Neto em A utopia possipel - Missões jesuíticas em Guairá, Itatim e Tape, 1609-1767, e seu suporte econômico-ecológico.

Barbara Freitag é professora titular do Departamento de Sociologia da Universidade de Brasília (UnB) e professora livre-docente da Universidade de Berlim, Alemanha. @-bfreitag@uol.com.br 